\title{
Tegmental Pontine Hemorrhages: Clinical Features and Prognostic Factors
}

\author{
Marcelo Lancman, Jorge Norscini, Hripsime Mesropian, \\ Carlos Bardeci, Toselli Bauso and Rubens Granillo
}

\begin{abstract}
We report six patients with partial, predominantly paramedian, tegmental pontine hemorrhages. Constant clinical manifestations consisted of: ipsilateral miosis, horizontal gaze paresis, lower motor neuron facial paresis, contralateral hemisensory loss and mild and transitory hemiparesis, dysarthria and mild or no compromise of consciousness. Five out of six were hypertensive. All patients survived with mild sequelae, oculomotor disturbances being the most persistent deficit. We found in our patients that a transverse diameter of less than $17 \mathrm{~mm}$, unilaterality of the injury and absence of coma were the major indicators of a favorable outcome.
\end{abstract}

RÉSUMÉ: Hémorragie de la décussation du pont: caractéristiques cliniques et facteurs pronostiques. Nous rapportons les cas de 6 patients avec hémorragies partielles, à prédominance paramédiane, de la décussation du pont. Les manifestations cliniques retrouvées invariablement étaient un myosis ipsilatéral, une parésie du regard horizontal, une parésie du neurone moteur inférieur, une perte de sensibilité à l'hémicorps contralatéral et une hémiparésie légère et transitoire, de la dysarthrie et une atteinte légère ou une absence d'atteinte de la conscience. Cinq sur six des patients étaient hypertendus. Tous les patients ont survécu avec des séquelles, les perturbations oculomotrices étant la séquelle la plus persistante. Nous avons constaté chez nos patients qu'un diamètre transverse de moins de $17 \mathrm{~mm}$, une lésion unilatérale et l'absence de coma étaient les indicateurs majeurs d'une issue favorable.

Can. J. Neurol. Sci. 1992; 19: 236-238

Pontine hemorrhages account for about $5-10 \%$ of intraparenchymal hemorrhages. ${ }^{1-4}$ Most frequently the hemorrhage is massive ${ }^{5-8}$ producing a classical syndrome characterized by coma, respiratory abnormalities, small reactive pupils, lack of horizontal ocular movements and quadriplegia..$^{2.5 .6 .9-11}$ Since the advent of computed tomography (CT), partial pontine hemorrhages $(\mathrm{PPH})$ have been increasingly recognized ${ }^{12-15}$ as presenting a different clinical course and favorable prognosis.

We studied six patients with spontaneous tegmental pontine hemorrhages (TPH) documented by CT, in which similar clinical signs and characteristics were identified.

\section{METHODS}

We studied six patients with spontaneous tegmental pontine hemorrhages (TPH) admitted to the Buenos Aires Italian Hospital between January 1st, 1979 and August 1st, 1989. Diagnosis was based on clinical and CT findings. One patient had magnetic resonance imaging (MRI) performed. None had evidence of trauma, tumor or blood dyscrasia.

\section{Results}

There were four men and two women whose ages ranged from 41 to 78 years (average 59.8). Hypertension was present in five patients, diabetes mellitus and moderate alcohol intake in two and chronic renal failure in one. Onset was sudden in all patients. Nausea, vomiting and headache were present in four cases. Three had sensory disturbances and one complained of diplopia. On admission, four patients were somnolent and two were alert; none of the patients progressed to coma. Bilateral small pupils were found in three patients and ipsilateral miosis in the remainder. One of them had ipsilateral ptosis. Two patients had bilateral horizontal gaze paresis and the remainder had ipsilateral horizontal gaze paresis. Three patients had upward gaze paresis with upbeat nistagmus. Internuclear ophthalmoplegia was found in two cases, being in the same side of the horizontal gaze palsy, making it a one and a half syndrome. Paralytic pontine extropia was found to be associated with the one and a half syndrome in one patient (patient 1). Skew deviation was present in one patient. Ocular bobbing occurred in one patient early during the course (Table 1). All patients had ipsilateral lower motor neuron facial paresis, and mild contralateral transient hemiparesis and hypoesthesia. Five patients had dysarthria and two had a bilateral cerebellar syndrome. In all cases, CT showed an unilateral hyperdense image located in the tegmental region, some of them paramedian in location. In patient one, MRI studies demonstrated an hyperintense signal on T1-weighted image involving the right pontine tegmentum

From the Department of Neurology, Hospital Italiano, Buenos Aires, Argentina

Received July 5, 1991. Accepted in final form November 6, 1991

Reprint requests to: Marcelo E. Lancman, M.D., Department of Neurology, Bowman Gray School of Medicine, 300 s Hawthorne Rd., Winston-Salem, North Carolina, U.S.A. 27103 
(Figure 1). The size of the hematomas varied from 12 to $17 \mathrm{~mm}$. All patients survived with mild sequelae; oculomotor disturbances were the most persistent deficit. The mean follow-up duration was of 13.8 months (Table 2).

\section{DisCUSSION}

The frequency of reported cases of TPH has increased since the use of CT. ${ }^{8.17-21}$ Prior to CT, it is conceivable that these cases were probably interpreted as ischemic etiology because of their favorable outcome. The clinical findings described in TPH were diverse. Some authors classified them according to their location. Kushner and Bressman ${ }^{21}$ described a dorsolateral tegmental and a hemipontine syndrome. Caplan and Goodwin ${ }^{18}$ mentioned three different locations of pontine hemorrhages: lateral tegmental, lateral basis pontine and paramedian syndromes. Three patients with lateral tegmental brainstem hemorrhages were described by these authors and a review of the literature

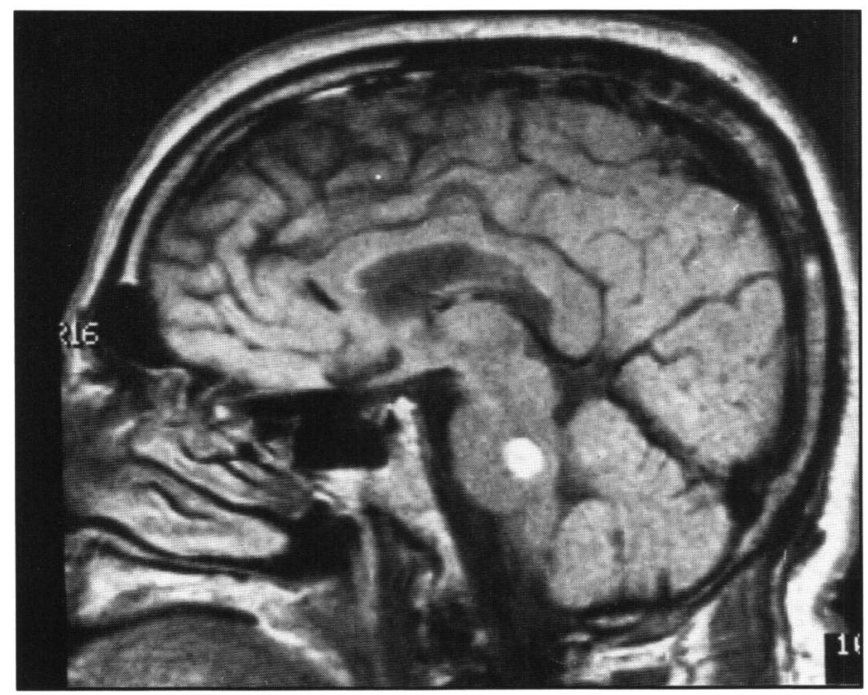

$\boldsymbol{A}$

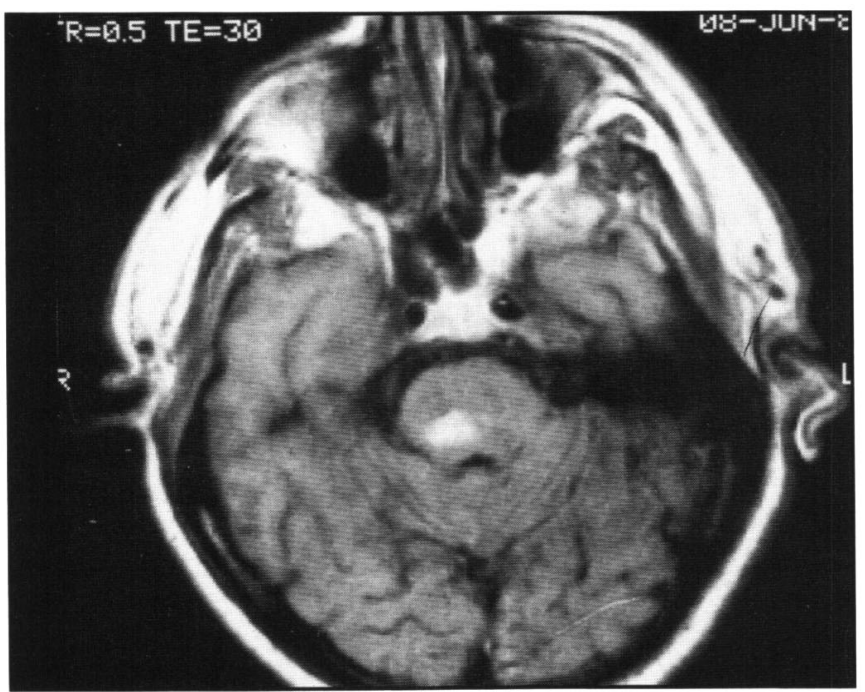

B was made, concluding that there was evidence for an homogeneous syndrome to be recognized premortem. Our six patients had clinical features similar to their cases, ${ }^{18}$ although some differences were seen in our patients, probably due to the predominant paramedian location of the hemorrhage.

\begin{tabular}{|c|c|c|c|}
\hline Patient & Pupils & Lateral Gaze & $\begin{array}{c}\text { Internuclear } \\
\text { Ophthalmoplegia }\end{array}$ \\
\hline 1 & $\begin{array}{l}\text { Ipsilateral } \\
\text { miosis }\end{array}$ & $\begin{array}{c}\text { Ipsilateral } \\
\text { paresis }\end{array}$ & $\begin{array}{l}+ \\
\text { (One and a half syndrome } \\
\text { with paralytic pontine } \\
\text { extropia) }\end{array}$ \\
\hline 2 & $\begin{array}{r}\text { Bilateral } \\
\text { miosis }\end{array}$ & $\begin{array}{l}\text { Bilateral } \\
\text { paresis }\end{array}$ & - \\
\hline 3 & $\begin{array}{l}\text { Ipsilateral } \\
\text { miosis }\end{array}$ & $\begin{array}{c}\text { Ipsilateral } \\
\text { paresis }\end{array}$ & $\stackrel{+}{+}$ \\
\hline 4 & $\begin{array}{l}\text { Bilateral } \\
\text { miosis }\end{array}$ & $\begin{array}{l}\text { Bilateral } \\
\text { paresis }\end{array}$ & - \\
\hline 5 & $\begin{array}{l}\text { Bilateral } \\
\text { miosis }\end{array}$ & $\begin{array}{c}\text { Ipsilateral } \\
\text { paresis }\end{array}$ & - \\
\hline 6 & $\begin{array}{c}\text { Ipsilateral } \\
\text { miosis }\end{array}$ & $\begin{array}{c}\text { Ipsilateral } \\
\text { paresis }\end{array}$ & - \\
\hline Patient & \multicolumn{2}{|c|}{ Vertical Gaze } & Other Findings \\
\hline 1 & \multicolumn{2}{|c|}{$\begin{array}{l}\text { Paresis with upbeat } \\
\text { nystagmus in upgaze }\end{array}$} & Ocular bobbing \\
\hline 2 & \multicolumn{2}{|c|}{$\begin{array}{l}\text { Paresis with upbeat } \\
\text { nystagmus in upgaze }\end{array}$} & - \\
\hline 3 & \multicolumn{2}{|c|}{$\begin{array}{l}\text { Paresis with upbeat } \\
\text { nystagmus in upgaze }\end{array}$} & - \\
\hline 4 & \multicolumn{2}{|c|}{-} & - \\
\hline 5 & \multicolumn{2}{|l|}{ - } & - \\
\hline 6 & \multicolumn{2}{|l|}{-} & - \\
\hline
\end{tabular}

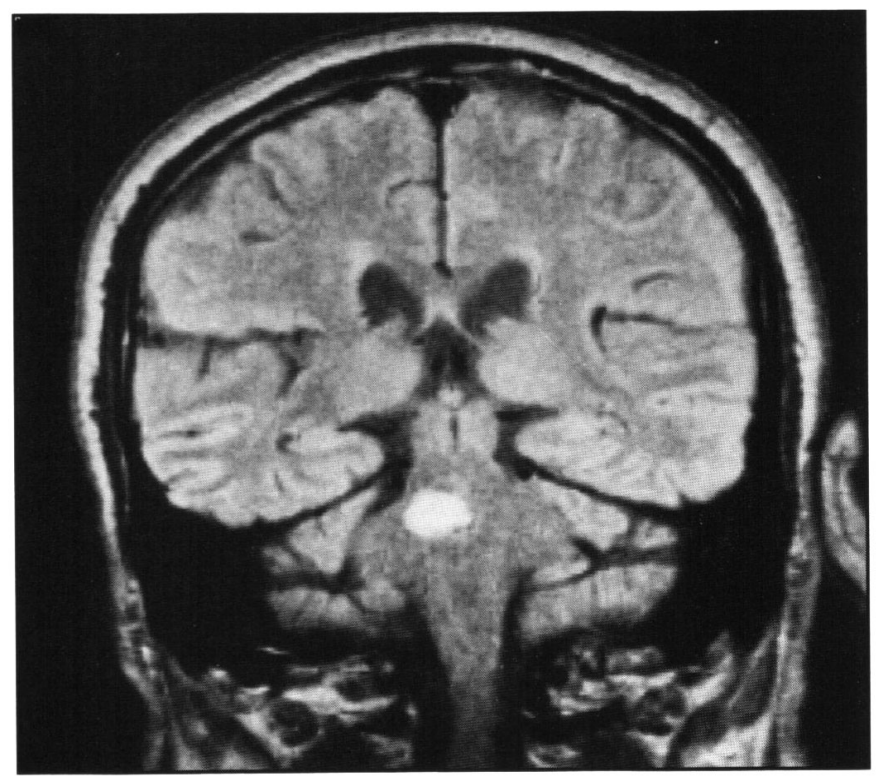

C

Figure I-(A) Saggital, (B) axial and (C) coronal TI weighted images showing an area of hyperintensity on the right paramedian tegmental pons in patient 1 . 
Table 2. Clinical Features

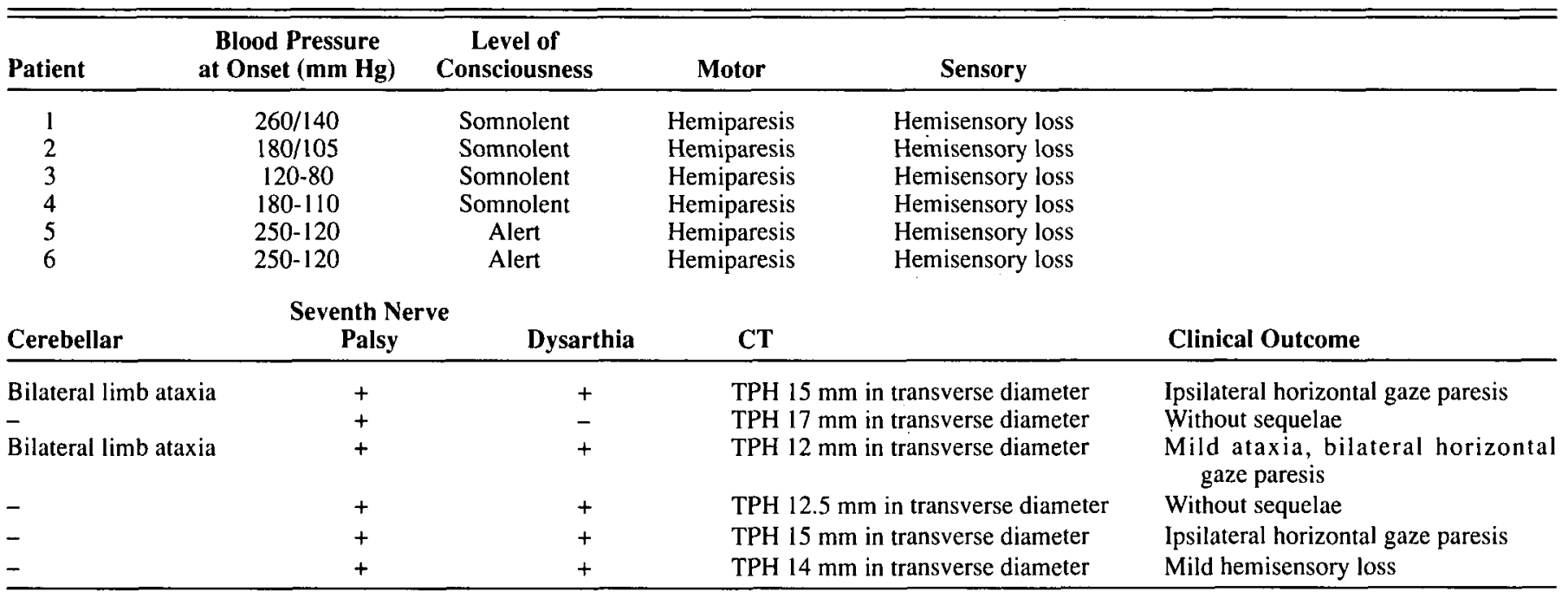

Five out of six patients had prior history of hypertension in accordance with previous reports in which it has been found in $60-90 \%$ of the cases. ${ }^{7.16 .18,21,22}$

Prognosis was good, with almost complete recovery in all cases. In other reports preservation of the level of consciousness and the unilaterality of the bleeding were indicators of good prognosis of the pontine hemorrhages. ${ }^{2,16.18-21}$ Nasiyama et al. ${ }^{19}$ related a less than $20 \mathrm{~mm}$ transverse diameter to a good prognosis. On the other hand, Del Brutto et al..$^{23}$ found the level of consciousness of the patients and the size of the hemorrhage to have no consistent bearing on outcome. We found in our patients that a transverse diameter less than $17 \mathrm{~mm}$, unilaterality of the injury and absence of coma were major indicators of favorable outcome.

Treatment was conservative in all our patients. Surgery in certain cases of pontine hematomas has been proposed by some authors. ${ }^{24-27}$ We believe this procedure unnecessary due to the excellent outcome of hemorrhages in this location.

\section{ACKNOWLEDGEMENTS}

The authors wish to thank Dr. José Biller for his critical revision of this manuscript.

\section{REFERENCES}

1. Ojemann RG, Mohr JP. Hypertensive brain hemorrhage. Clin Neurosurg 1976; 23: 220-224.

2. Silverstein A. Primary pontine hemorrhage. In: Vinken F, Bruyn G, eds. Handbook of Clinical Neurology, vol 12, part 2. Amsterdam: North Holland 1972; 37-53.

3. Mutlu N, Berry RG, Alpers BJ. Massive cerebral hemorrhage. Arch Neurol 1963; 8: 644-661.

4. Brewer DB, Fawcett FJ, Horsfield GI. A necropsy series of nontraumatic cerebral hemorrhages and softenings, with particular reference to heart weight. J Pathol Bact 1968; 96: 311-320.

5. Steegmann AT. Primary pontine hemorrhages. J Nerv Ment Dis 1951; 114: 35-65.

6. Fang H, Foley J. Hypertensive hemorrhages of the pons and cerebellum. Trans Am Neurol Assoc 1954; 79: 126-130.

7. Fisher CM. Pathological observations in hypertensive cerebral hemorrhage. J Neuropathol Exp Neurol 1971; 30: 536-550.

8. Goto N, Kaneko M, Hosaka Y, Koga H. Primary pontine hemorrhage: clinico-pathological correlations. Stroke 1980; 11: 84-90.
9. Epstein AW. Primary massive pontine hemorrhage. J Neuropathol Exp Neurol 1951; 10: 426-448.

10. Caplan L. Intracerebral hemorrhage. In: Tyler II, Dawson D, eds. Current Neurology, vol 2. Boston: Houghton-Mifflin 1979; 185205.

11. Fisher CM. The pathology and pathogenesis of intracerebral hemorrhage. $I n$ : Fields W, ed. Pathogenesis and Treatment of Cerebrovascular Disease, 7th Annual Scientific Meeting of the Houston Neurological Society, Texas Medical Center, Houston, TX. Springfield, IL: Charles C, Thomas 1961; 295-317.

12. Muller $H$, Wurthrich $R$, Wiggle $U$, Hunig R, Elke $M$. The contribution of computerized axial tomography to the diagnosis of cerebellar and pontine hematomas. Stroke 1975; 6: 467-475.

13. Gobernado J, De Molina A, Gimeno A. Pure motor hemiplegia due to hemorrhage in the lower pons. Arch Neurol 1980; 4: 557-558.

14. Kase C, Maulsby G, Mohr J. Partial pontine hematomas. Neurology 1981; 30: 652-655.

15. Payne $H$, Maraville K, Levinstone A, Tindall R. Recovery from primary pontine hemorrhages. Ann Neurol 1978; 4: 557-558.

16. Dinsdale H. Spontaneous hemorrhage in the posterior fossa. Arch Neurol 1964; 10: 200-217.

17. Tyler H, Johnson P. Case records of the Massachusetts General Hospital 36-1972. N Engl J Med 1972; 287: 506-512.

18. Caplan LR, Goodwin JA. Lateral tegmental brainstem hemorrhages. Neurology 1982; 32: 252-260.

19. Nasiyama S, Niizuma H, Suzuki J. Pontine hemorrhage: a clinical analysis of 26 cases. J Neurol Neurosurg Psychiatry 1985; 48: 658-662.

20. Kudo Y, Fukai M, Yamadori A. Asterixis due to pontine hemorrhage. J Neurol Neurosurg Psychiatry; 48: 487-489.

21. Kushner MJ, Bressman SB. The clinical manifestation of pontine hemorrhage. Neurology 1985; 35: 637-643.

22. Caplan L, Mohr J. Intracerebral hemorrhage: an update. Geriatrics 1978; 33: 42-52.

23. Del Brutto $\mathrm{OH}$, Noboa $\mathrm{CA}$, Barinagarrementeria F. Lateral pontine hemorrhages: reappraisal of benign cases. Stroke 1978; 18: $954-$ 956.

24. Murphy MG. Successful evacuation of acute pontine hematoma. J Neurosurg 1972; 37: 224-225.

25. Koss WT, Sunder-Plassmann M, Salah S. Successful removal of a large intrapontine hematoma. J Neurosurg 1969; 31: 690-694.

26. Kowada M, Yamaguchi K, Ito Z, Matsouka S. Pneumoenceph. tomography of operated primary pontine hemorrhage with long survival: Report of two cases. J Neurol Neurosurg Psychiatry 1972; 35: 243-246.

27. Burns J, Lisak R, Schut L, Silbarberg D. Recovery following brainstem hemorrhage. Ann Neurol 1980; 7: 183-184. 